Supplementary Materials for

\title{
Nanoparticle size influences antigen retention and presentation in lymph node follicles for humoral immunity
}

Yi-Nan Zhang ${ }^{1,2}$, James Lazarovits*1,2, Wilson Poon*1,2, Ben Ouyang*1,2,3 ${ }^{*}$ Luan N.M. Nguyen ${ }^{1,2}$, Benjamin R. Kingston ${ }^{1,2}$, Warren C.W. Chan** ${ }^{1,2,4,5,6}$

${ }^{1}$ Institute of Biomaterials \& Biomedical Engineering, University of Toronto, Toronto, ON M5S 3G9, Canada

${ }^{2}$ Terrence Donnelly Centre for Cellular \& Biomolecular Research, University of Toronto, Toronto, ON M5S 3E1, Canada

${ }^{3} \mathrm{MD} / \mathrm{PhD}$ Program, University of Toronto, Toronto, ON M5S 1A8, Canada

${ }^{4}$ Department of Chemical Engineering \& Applied Chemistry, University of Toronto, Toronto, ON M5S 3E5, Canada

${ }^{5}$ Department of Materials Science \& Engineering, University of Toronto, Toronto, ON M5S

1A1, Canada

${ }^{6}$ Department of Chemistry, University of Toronto, Toronto, ON, M5S 3H6, Canada

*These authors contributed equally to this work

** Corresponding author: warren.chan@utoronto.ca.

\section{Materials and Methods:}

\section{Synthesis of gold nanoparticles}

$5 \mathrm{~nm}$ gold nanoparticles (AuNPs) were synthesized according to previously developed methods ${ }^{1}$. In brief, $50 \mu \mathrm{L}$ of $10 \%$ HAuCl4 (Sigma-Aldrich S4641) was diluted in $40 \mathrm{~mL}$ of deionized $\mathrm{H}_{2} \mathrm{O}$. The solution was stirred and heated to $60^{\circ} \mathrm{C}$ for 50 minutes. Meanwhile, reducing solution containing $3 \mathrm{~mL} \mathrm{1 \%}$ sodium citrate tribasic (Sigma-Aldrich S4641), $1.125 \mathrm{~mL} \mathrm{1 \% (w/v)} \mathrm{tannic}$ acid (Sigma-Aldrich 1401554), and $1.125 \mathrm{~mL} 25 \mathrm{mM}$ potassium carbonate (Sigma-Aldrich 367877 ) diluted in $9.5 \mathrm{~mL}$ deionized $\mathrm{H}_{2} \mathrm{O}$ was heated in a water bath at $60^{\circ} \mathrm{C}$ for 50 minutes. Then, $10 \mathrm{~mL}$ of the reducing solution was added into the $\mathrm{HAuCl}_{4}$ containing flask. The reaction was maintained at $60^{\circ} \mathrm{C}$ for 30 minutes, followed by $100^{\circ} \mathrm{C}$ for 10 minutes. The solution was then cooled on ice to room temperature. $1 \mathrm{~mL}$ of $40 \mathrm{mg} / \mathrm{mL}$ bis(p-sulfonatophenyl)phenylphosphine dihydrate dipotassium salt (Sigma-Aldrich 698539) was added to the reaction flask and allowed to stir overnight. The next day, AuNPs were washed three times by ultracentrifugation (Beckman Coulter's Optima MAX-XP) and resuspension of the pellet in $0.02 \%$ sodium citrate tribasic, $0.02 \%$ Tween-20 (BioShop TWN510). The centrifugation speed was 150,000 g. AuNPs were then stored at $4^{\circ} \mathrm{C}$ before use.

$15 \mathrm{~nm}$ AuNPs were synthesized using a method adapted from Frens ${ }^{2}$. In brief, $1 \mathrm{~mL}$ of $3 \%$ (w/v) sodium citrate tribasic was diluted in $100 \mathrm{~mL}$ deionized water and heated to a boil. $100 \mu \mathrm{L}$ of $10 \%$ (w/v) aqueous $\mathrm{HAuCl}_{4}$ was then added under vigorous stirring. The reaction was maintained for 10 minutes and immediately cooled on ice to room temperature. $15 \mathrm{~nm}$ AuNPs were then used to seed the growth of larger AuNP sizes. The synthesis of $50 \mathrm{~nm}$ and $100 \mathrm{~nm}$ AuNPs were described 
previously by our group ${ }^{3}$. Briefly, molar equivalents of sodium citrate tribasic $\left(1.5 \times 10^{-2}\right.$ $\mathrm{M})$, aqueous $\mathrm{HAuCl}_{4}\left(2.5 \times 10^{-2} \mathrm{M}\right)$, and $15 \mathrm{~nm}$ AuNPs $\left(2-4 \times 10^{-9} \mathrm{M}\right)$ were diluted in 100-500 $\mathrm{mL}$ deionized water at room temperature. The appropriate molar equivalent of hydroquinone (Sigma-Aldrich H17902) $\left(2.5 \times 10^{-2} \mathrm{M}\right)$ was rapidly added to the solution under vigorous stirring. The reaction was maintained overnight. In the following day, $1-5 \mathrm{~mL}$ of $5 \%(\mathrm{w} / \mathrm{v})$ Tween-20 was added to the solution and stirred for 10 minutes. AuNPs were washed two times by centrifugation and resuspension of the pellet in $0.02 \%$ sodium citrate tribasic and $0.05 \%$ Tween-20. The centrifugation speeds ranged from 500-10000 g depending on the AuNP size. AuNPs were then stored at $4^{\circ} \mathrm{C}$ before use.

\section{Synthesis of nanoparticle conjugated vaccines}

Nanoparticle conjugated vaccines were synthesized using different sizes of spherical AuNPs conjugated to ovalbumin (OVA) (Sigma-Aldrich A5503) antigen. Before protein conjugation, nanoparticle stock was washed once in $0.02 \%$ sodium citrate tribasic for 35 minutes. $100 \mathrm{mM}$ sodium citrate tribasic solution and $\mathrm{HCl}$ was mixed and $\mathrm{pH}$ was adjusted to 2.3. This solution was then diluted to $20 \mathrm{mM}$ of sodium citrate tribasic (pH 3) and mixed with $10 \mathrm{mg} / \mathrm{mL}$ pre-solubilized OVA in PBS. After that, OVA in $20 \mathrm{mM}$ of sodium citrate tribasic (pH 3) was rotated for 2 hours and filtered using a $0.22 \mu \mathrm{m}$ PES filter. AuNPs with $1.6 \times 10^{16} \mathrm{~nm}^{2}$ total surface area was added to $250 \mu \mathrm{L}$ OVA solution and incubated at $37^{\circ} \mathrm{C}$ for 1 hour. The solution was topped up to $1.2 \mathrm{~mL}$ with $500 \mu \mathrm{L}$ of $1 \times \mathrm{PBS}+0.05 \%$ Tween-20 (PBST). The $5 \mathrm{~nm}$ AuNPs conjugated to OVA was purified using $100 \mathrm{kDa}$ Amicon tube with the centrifugation speed of $4000 \mathrm{~g}$ for 5 minutes. The other sizes $(15,50$, and $100 \mathrm{~nm})$ of AuNPs conjugated to OVA was purified in $1.5 \mathrm{~mL}$ Eppendorf tube with centrifugation speeds of 5000, 600, and $200 \mathrm{~g}$ respectively for 60 minutes. OVA-AuNPs were washed three times by centrifugation using PBST buffer. OVA-AuNPs were finally resuspended in sterile PBS. OVA-AuNP vaccine was filtered using a $0.22 \mu \mathrm{m}$ PES filter and the concentration was re-adjusted before footpad intradermal administration.

\section{PEGylation of gold nanoparticles}

AuNPs suspended in $0.02 \%$ sodium citrate tribasic, $0.02 \%$ Tween- 20 were mixed with $2 \mathrm{kDa}$ thiol-methoxyl heterobifunctionalized PEG $\left(\mathrm{CH}_{3} \mathrm{O}-\mathrm{PEG}_{2 \mathrm{kDa}}-\mathrm{SH}\right)$ (Laysan Bio, Inc MPEG-SH$2000)$ and $5 \mathrm{kDa}$ amine-thiol heterobifunctioanlized PEG $\left(\mathrm{NH}_{2}-\mathrm{PEG}_{5 \mathrm{kDa}}-\mathrm{SH}\right)$ (Rapp Polymere 135000-40-20) at a 4:1 molar ratio with a total poly(ethylene) glycol (PEG) density of 5 PEG/nm . The reaction was allowed to proceed in a $60^{\circ} \mathrm{C}$ water bath for 1 hour. The $5 \mathrm{~nm}$ PEGylated AuNPs were purified in $0.1 \mathrm{M}$ sodium bicarbonate $(\mathrm{pH} 8.4$ ) and $0.05 \%$ Tween-20 buffer using ultracentrifugation at the speed of 220,000 g for 45 minutes. $50 \mathrm{~nm}$ PEGylated AuNPs were purified with centrifugation speed of $2000 \mathrm{~g}$ for 35 minutes. The purified PEGylated AuNPs were then mixed with Cy5 NHS Ester (Click Chemistry Tools 1076-100) in a 2:1 ratio between the amounts of the $5 \mathrm{kDa}$ mPEG-SH and NHS-Cy5. The reaction proceeded on a rotator overnight protected from light. Cy5 conjugated to PEG-AuNPs were purified using PBST for four times by centrifugation. Pellets were resuspended in sterile PBS before injection. PEGylated AuNPs were stored at $4^{\circ} \mathrm{C}$ and protected from ambient light before use.

\section{Physicochemical characterization of gold nanoparticles and nanoparticle vaccines}

The core size of AuNPs, OVA-AuNPs, and PEG-AuNPs were characterized by transmission electron microscopy (TEM) (Fig. S1 and Table. S1). $5 \mu \mathrm{L}$ of nanoparticle stock was added on the plasma treated copper grids (Ted Pella 01813-F). After 3 minutes, the samples were blotted and 
left undisturbed for 10 minutes to be completely air-dried. To visualize the protein conjugated layer on the AuNP core, OVA-AuNP sample on the TEM grid were washed one time with $5 \mu \mathrm{L}$ deionized water before negatively stained with $3 \mu \mathrm{L}$ of $1 \%$ uranyl acetate (Ted Pella 19481). The stained samples were blotted after 1 minutes of staining and air dried for another 10 minutes. All samples were tested using TEM at $200 \mathrm{kV}$ (Tecnai 20, FEI, Hillsboro, OR, USA) and imaged using an AMT 16000 camera. The average nanoparticle core sizes were determined by measuring over 100 particles using ImageJ (NIH, Maryland) ${ }^{4}$. The hydrodynamic diameters were characterized using dynamic light scattering (DLS) (Malvern Instruments Ltd., Worcestershire, UK) and UVvisible absorbance spectroscopy (UV-Vis) (Shimadzu Scientific Instruments). The surface change was measured using Zetasizer Nano-ZS (Malvern Instruments Ltd.). The concentrations of nanoparticles were measured using UV-Vis. The conjugated OVA amount was determined by bicinchoninic acid (BCA) assay (ThermoFisher Scientific 23235).

\section{OVA protein extraction and quantification using bicinchoninic acid assay}

OVA-AuNPs (with $2 \times 10^{14} \mathrm{~nm}^{2}$ total surface area) resuspended in $25 \mu \mathrm{L}$ PBS were added to $8 \mu \mathrm{L}$ of $4 \%$ NuPAGE LDS buffer (ThermoFisher Scientific NP0007) and $4 \mu \mathrm{L}$ of $500 \mathrm{mM}$ dithiothreitol (DTT) (BioShop DTT001.5). This solution was incubated at $70^{\circ} \mathrm{C}$ for 1 hour. After 1 hour, the particles were centrifuged at $18,000 \mathrm{~g}$ for 15 minutes. The supernatant was retrieved and solubilized in $25 \mu \mathrm{L}$ of $2 \%$ (w/v) sodium dodecyl sulfate (SDS) (ThermoFisher Scientific NP0001). To remove the SDS and DTT from protein isolates, $950 \mu \mathrm{L}$ of $10 \%$ (w/v) trichloroacetic acid (TCA) (Sigam-Aldrich T6399) in acetone was added into the Eppendorf with protein isolates and incubated at $-80^{\circ} \mathrm{C}$ for 12 hours. The samples were centrifuged down at $18,000 \mathrm{~g}$ at $4^{\circ} \mathrm{C}$ for 15 minutes to pellet the protein. The supernatant was discarded, and the protein pellet was resuspended in $500 \mu \mathrm{L}$ of $0.03 \%$ (w/v) deoxychol (Sigma-Aldrich 30970) and vortexed thoroughly. $100 \mu \mathrm{L}$ of $72 \%$ (w/v) TCA was added and incubated on ice for 30 minutes to allow protein precipitation. Samples were centrifuged again at $18,000 \mathrm{~g}$ at $4^{\circ} \mathrm{C}$ for 15 minutes. The washed pellet was then topped up with $950 \mu \mathrm{l}$ of acetone at $-30^{\circ} \mathrm{C}$. Samples were vortexed thoroughly and incubated at $-80^{\circ} \mathrm{C}$ for 1 hour. The precipitated protein was centrifuged to the bottom at $18,000 \mathrm{~g}$ at $4^{\circ} \mathrm{C}$ for 15 minutes. The supernatant was discarded and the purified protein pellet was air dried. These purified protein samples were dissolved in a $2 \%(\mathrm{w} / \mathrm{v})$ SDS solution in PBS. At the same time, OVA was dissolved in the same SDS solution and diluted stepwise for the standard curve. The OVA standards and purified protein samples were incubated again at $70^{\circ} \mathrm{C}$ for 1 hour. $200 \mu \mathrm{L}$ of the bicinchoninic acid (BCA) (ThermoFisher Scientific 23235) working reagent provided in the kit was added to samples, standards and controls. They were incubated at $60^{\circ} \mathrm{C}$ for 30 minutes until a purple colour developed. The samples were cooled to room temperature and scanned on an absorbance plate reader at $562 \mathrm{~nm}$ (Tecan Sunrise). The estimated total protein content was calculated based on the standard curve. The final footpad injection dose was normalized based on the same total amount of OVA antigen $(10 \mu \mathrm{g})$ for each size as determined by the BCA assay described here (Fig. S3).

\section{Animal care}

All animal experiments were performed according to the protocols approved by the University of Toronto Division of Comparative Medicine and Animal Care Committee (protocol numbers: 20011620, 20011910, 20012102). 6 to 10-week old wild type C57BL/6 mice were purchased form Charles River Laboratories (Montreal, Canada) and The Jackson Laboratory (Maine, USA). The genetically modified female C57BL/6 C3 (Jax stock \#003641), Cr2 (Jax stock \#008225) and CD19 
(Jax stock \#006785) knockout (KO) mice were purchased from The Jackson Laboratory. Mice were anesthetized using isoflurane (3\%) carried with oxygen during injection. OVA-AuNP vaccines and PEG-AuNPs were injected into the intradermal footpads of mice using a 29-gauge insulin needle (Fig. S2). The injection dose was normalized to the same conjugated OVA amount $(10 \mu \mathrm{g})$ and the injection volume was $20 \mu \mathrm{L}$ for each footpad. 4 footpads were injected, and sentinel lymph nodes were further studied.

\section{Histology, immunostaining and imaging}

The mice were sacrificed after different injection times (from 2 hours to 8 weeks). The sentinel (axillary, brachial and popliteal) lymph nodes were collected for histological analysis. To preserve the antigens on cell membrane and on nanoparticles, the isolated fresh lymph nodes were directly placed into frozen section compound (VWR® International, LLC 95057-838) in a plastic cryomold (Tissue-Tek® at VWR® 4565) and frozen with liquid nitrogen. The frozen samples were taken to the Toronto Centre for Phenogenomics (TCP) on dry ice for further sample processing. $8 \mu \mathrm{m}$ tissue sections were cut on Cryostar NX70 and placed on charged slides. Tissue sections were stained using silver enhancement kits (Ted Pella, Inc. 15718) to enhance gold nanoparticle signal. For immunostaining, tissue sections were stained for follicular dendritic cells (FDCs) using anti-CD21 antibody (Abcam 75985) and/or anti-FDC-M1 antibody (BD Biosciences 551320), for B cells using anti-B220 antibody (eBioscience 14-0452-82), and for subcapsular sinus macrophages using anti-sialoadhesin (CD169) antibody (Abcam 53443). To verify if OVA antigen is still intact with gold nanoparticles, tissue sections were stained with anti-ovalbumin antibody (FITC) (Abcam 85584) to visualize OVA antigens location. To verify germinal center formation, tissue sections were stained with anti-GL7 antibody (FITC) (BioLegend 144604). Tissue sections were then counter stained with DAPI.

The stained tissue sections were scanned using an Olympus VS-120 slide scanner and imaged using a Hamamatsu ORCA-R2 C10600 digital camera for all bright-field, fluorescent and darkfield images. The bright-field images of silver stained nanoparticles in lymph node follicles were quantified using ImageJ $(\mathrm{NIH})^{4}$. The threshold of all silver stained images was set up the same value for each. The total area of the silver stained area was then determined and compared across all conditions. To colocalize gold nanoparticle signal and immunostaining, dark-field images were used based on the scattering intensity from gold nanoparticles. Dark-field images ${ }^{5}$ of gold nanoparticle signal were used to colocalize the distribution of FDC networks, and OVA antigens in lymph node follicles.

\section{Tissue clearing}

Lymph node tissues were processed for tissue clearing as previously described ${ }^{6}$. Briefly, lymph nodes were extracted and placed into hydrogel monomer solution containing $4 \%$ formaldehyde (Bioshop Canada Inc. FOR201.500), 2\% w/v acrylamide (Bioshop Canada Inc AB1032), and $0.25 \%$ w/v VA-044 azo initiator (Wako Chemicals VA-044) in 1× PBS. The lymph nodes were incubated in the hydrogel monomer solution for 7 days at $4^{\circ} \mathrm{C}$. To crosslink the hydrogel monomer within the tissues, fresh hydrogel monomer solution was added to the samples, and then samples were degassed and purged with argon gas. The samples were incubated at $37^{\circ} \mathrm{C}$ for 3 hours. The hydrogel embedded lymph nodes were rinsed with PBS and then incubated in clearing solution containing 4\% w/v SDS in $200 \mathrm{mM}$ sodium borate solution (pH 8.5 with $0.1 \%$ Triton-X 100 
(Sigma-Aldrich X100) and $0.01 \%$ sodium azide (Bio Basic DB0613)) for 5 days at $50^{\circ} \mathrm{C}$. Samples were then placed in borate solution for storage at $4^{\circ} \mathrm{C}$.

Immunostaining of cleared tissues and three-dimensional light-sheet imaging

Immunostaining of cleared tissue was performed by blocking lymph node tissues with blocking buffer containing 5\% w/v bovine serum albumin (BSA) (Sigma-Aldrich A9418) in PBS, 0.1\% Triton X-100, $0.01 \%$ sodium azide. Lymph nodes were left in blocking solution at room temperature overnight. Next, primary CD21 antibody (Abcam 75985) was added to lymph nodes at a $1: 100$ dilution in $1 \mathrm{~mL}$ of PBS with $2 \% \mathrm{v} / \mathrm{v}$ goat serum, $0.1 \%$ Triton $\mathrm{X}-100$, and $0.01 \%$ sodium azide solution and incubated at room temperature for 2 days. Tissues were then washed for 24 hours with PBS, $0.1 \%$ Triton X-100, $0.01 \%$ sodium azide solution to remove excess primary antibody. Cy5 conjugated secondary antibody was then incubated with the lymph nodes at a 1:200 dilution as well as with DAPI (Sigma-Aldrich D9542) at a final concentration of $10 \mu \mathrm{M}$ in $2 \% \mathrm{v} / \mathrm{v}$ goat serum, PBS, $0.1 \%$ Triton-X 100, $0.01 \%$ sodium azide for 2 days at room temperature. The stained tissues were then washed with PBS, $0.1 \%$ Triton-X 100, $0.01 \%$ sodium azide solution for 24 hours to remove excess stain. Tissues are placed in $67 \% 2$ '2-thiodiethanol (TDE) solution in $200 \mathrm{mM}$ sodium borate, $0.1 \%$ Triton-X, $0.01 \%$ sodium azide solution for refractive index matching prior to light-sheet imaging. 3D light-sheet imaging of the cleared and stained lymph nodes was performed using the Zeiss Light-sheet Z.1 microscope using the CLARITY Plan-Neofluar Objective, 20X, NA 1.0, refractive index of 1.45 in 67\% TDE solution. Standard emission and filter lines were used for DAPI and CD21 detection. Dark-field imaging of gold nanoparticles was done as previously described by detecting scattering intensity from the metallic nanoparticles ${ }^{5}$. The 3D images were visualized using Bitplane IMARIS version 8.1.

\section{TEM study on lymph node tissues}

TEM was used to visualize the localization of nanoparticle distribution around FDCs in lymph node follicles at the subcellular level. The mice were sacrificed after different injection times (from 2 hours to 8 weeks). The sentinel lymph nodes were collected and directly fixed with $4 \%$ formaldehyde and $0.5 \%$ glutaraldehyde (Sigma-Aldrich 340855) in PBS at room temperature for 1 hour. The samples were then stored at $4^{\circ} \mathrm{C}$. Fixed lymph node samples were sent to the Nanoscale Biomedical Imaging Facility at The Hospital for Sick Children for further processing. The lymph node samples were mounted and sectioned, then placed on copper grids. Samples were then negative stained with $2 \%$ uranyl acetate (Ted Pella 19481). The morphology of FDCs and nanoparticle localization of lymph node sections were imaged using TEM at $200 \mathrm{kV}$. The numbers of nanoparticles on FDC dendrites were quantified using TEM images. In brief, the area $\left(\mathrm{um}^{2}\right)$ of FDC dendrites were measured using ImageJ $(\mathrm{NIH})^{4}$. The total numbers of gold nanoparticle within the area of FDC dendrites were calculated using ImageJ by setting up the same threshold value. The numbers of OVA protein conjugated on different sizes of AuNPs were previously quantified using BCA (Fig. S3). The total amount of conjugated antigen on FDC dendrites for each size was then calculated.

\section{Lymph node disaggregation and cell staining and flow cytometry}

Total number of $\mathrm{GL} 7^{+} \mathrm{B} 220^{+}$germinal center B cells were quantified using flow cytometry (Fig. S20-21). The mice were immunized using different sizes of OVA-AuNP vaccines and sacrificed at 5 weeks. The sentinel lymph nodes were isolated and mechanically disaggregated using a razor blade. After that, these lymph nodes were enzyme disaggregated into single cell suspension using 
$4790 \mu \mathrm{L}$ of Hanks' Balanced Salt Solution (HBSS) buffer (ThermoFisher Scientific 14185052) with $200 \mu \mathrm{L}$ of $10 \mathrm{mg} / \mathrm{ml}$ collagenase IV (Sigma-Aldrich C5138) and $10 \mu \mathrm{L}$ of $10 \mathrm{mg} / \mathrm{mL}$ of DNase (Roche 10104159001) in an Eppendorf tube. These samples were incubated and rotated at $37^{\circ} \mathrm{C}$ for 30 minutes. The disaggregated lymph node cells were passed through a $70 \mu \mathrm{m}$ cell strainer and centrifuged at $300 \mathrm{~g}$ at $4^{\circ} \mathrm{C}$ for 10 minutes. The supernatant was discarded, and cell pellet was resuspended in HBSS blocking buffer supplemented with $0.5 \%(\mathrm{w} / \mathrm{v})$ bovine serum albumin and $2 \mathrm{mM}$ EDTA. Cell suspension was stained with fluorescent labelled antibodies. AntiCD16/32 antibody (BioLegend 101302) was used for Fc receptor blocking. Antibodies stained for germinal center B cells including: Zombie NIR Live/Dead stain (BioLegend 423106), BV510 antiB220 (RA3-6B2) (BioLegend 103247), and Alexa Fluor® 647 anti-GL7 (BioLegend 144606). Cells were stained on ice for 30 minutes and followed by 2 washes using HBSS blocking buffer. Cells were then fixed using 1.6\% paraformaldehyde (Thermo Fisher Scientific 28906) in HBSS on ice for 30 minutes. Cells were resuspended in blocking buffer for flow cytometry. Cell stain events were acquired using a 5-laser BD LSR FORTESSA X-20 flow cytometer. Cell stain events were analyzed using FlowJo V10 software.

\section{ELISA of OVA-specific antibody production:}

OVA-specific antibody production was measured in the sera using enzyme-linked immunosorbent assay (ELISA) after immunization of different sizes of OVA-AuNP vaccines at 5 weeks. $100 \mu \mathrm{L}$ of OVA with a concentration of $20 \mu \mathrm{g} / \mathrm{mL}$ was pre-coated on MaxiSorp 96-well plate (Thermo Fisher Scientific 442404) at $4^{\circ} \mathrm{C}$ overnight. The solution was discarded, and the wells was washed one time with $400 \mu \mathrm{L}$ of PBST. After discarding the washing PBST, $200 \mu \mathrm{L}$ of $1 \times$ casein buffer (Sigma-Aldrich B6429-500ML) was added to block the wells at room temperature for 2 hours. The solution was discarded and washed one time with PBST. To perform serial dilution of the sera, $100 \mu \mathrm{L}$ of $0.5 \times$ casein buffer was added into the lanes except the $1^{\text {st }}$ one. The serum samples were first diluted 100 times with $0.5 \times$ Casein buffer and then added into the $1^{\text {st }}$ lane of the plate (200 $\mu \mathrm{L})$. The samples were then serially diluted until the second final lane. The last lane was kept as a control without serum samples. Samples were then incubated at room temperature for 1 hour. The wells were washed two times using PBST. Goat anti-mouse IgG secondary antibody, horseradish peroxidase (HRP) (Thermo Fisher Scientific 31430) was diluted 5000 times. The diluted HRP solution $(100 \mu \mathrm{L})$ was then added into wells and incubated at room temperature for 1 hour. The wells were washed two times using PBST. $100 \mu \mathrm{L}$ TMB (3,3',5,5;-tetramethylbenzidine) chromogen solution (Thermo Fisher Scientific 002023) was added into each well and incubated at room temperature for 20 minutes. The blue color was developed, and the reaction was terminated by adding $1 \mathrm{M}$ sulfuric acid $(100 \mu \mathrm{L})$. The absorbance was measured using an absorbance plate reader at $450 \mathrm{~nm}$ (Tecan Sunrise). The reference was setup at $570 \mathrm{~nm}$. All titers reported are inverse dilutions where $\mathrm{A}_{450 \mathrm{~nm}}$ - A570 nm equals 0.1.

\section{Modified ELISA of C3 protein absorbed on nanoparticles}

C3 absorption on nanoparticles were measured using a modified ELISA ${ }^{7} .5 \mathrm{~nm}$ and $50 \mathrm{~nm}$ OVAAuNP vaccines were pre-coated onto MaxiSorp 96-well plate overnight at $4^{\circ} \mathrm{C}$. The pre-coated concentration was normalized by $5 \mu \mathrm{g} / \mathrm{mL}$ of OVA in $50 \mu \mathrm{L}$ of PBS. The solution was discarded, and the wells were washed one time with PBST. $1 \times$ casein buffer was used to block the wells at room temperature for 2 hours. The wells were washed one time with PBST. 30\% serum from wild type mice was added to each well and allowed to incubate at $37^{\circ} \mathrm{C}$ for 1 hour. Plates were washed two times. $1 \times$ HRP-conjugated anti-mouse complement C3 antibodies (Abcam 157711) were 
added into the wells and incubated at room temperature for 1 hour. The wells were then washed two more times using PBST. TMB was added into the wells and incubated at room temperature for 20 minutes. The reaction was stopped by adding sulfuric acid. The absorbance was then measured using a plate reader at $450 \mathrm{~nm}$ with the reference of $570 \mathrm{~nm}$. The optical density (OD) at $450 \mathrm{~nm}$ was determined.

To verify the C3 absorption on nanoparticles in vivo, OVA-AuNP vaccines were injected intradermally into the footpads of mice. The mice were sacrificed, and sentinel lymph nodes were isolated after 1 and 6 hours post-injection for 5 and $50 \mathrm{~nm}$ OVA-AuNP vaccines. These sentinel lymph nodes were mechanically disaggregated using a razor blade and passed through a $70 \mu \mathrm{m}$ cell strainer and centrifuged at $300 \mathrm{~g}$ at $4{ }^{\circ} \mathrm{C}$ for 10 minutes. The supernatant was collected and washed three times using HBSS buffer. To isolate the nanoparticles, samples of 5 and $50 \mathrm{~nm}$ OVAAuNPs were centrifugated with the speeds of $80,000 \mathrm{~g}$ and $600 \mathrm{~g}$ respectively for 60 minutes. The supernatant was discarded and nanoparticles were purified using PBST 3 times. The concentration of OVA-AuNPs was measured using UV-Vis and $5 \mu \mathrm{g} / \mathrm{mL}$ of OVA normalized nanoparticles in $50 \mu \mathrm{L}$ of PBS was coated on MaxiSorp 96-well plate at room temperature for 12 hours. Using the same protocol of in vitro modified ELISA, $1 \times$ Casein buffer was used to block the wells at room temperature for 2 hours. Plates were washed two times. 1× HRP-conjugated anti-mouse complement $\mathrm{C} 3$ antibody was added into wells and incubated at room temperature for 1 hour. After washing using PBST, TMB was added to establish the reaction for 20 minutes. The reaction was terminated by adding sulfuric acid. The OD was measured at $450 \mathrm{~nm}$ using a plate reader.

\section{Statistical analyses}

Data was collected from 4-8 mice per group. All statistical analyses and graphing were performed using GraphPad Prism 6.0. Data were analyzed using one-way ANOVA followed by Tukey's multiple comparisons test or an unpaired t test. Data are presented as mean \pm SD. $P<0.05$ is defined as significant: $* P<0.05 ; * * P<0.01 ; * * * P<0.001 ; * * * * P<0.0001$. 


\section{Supplementary Figures and Table:}
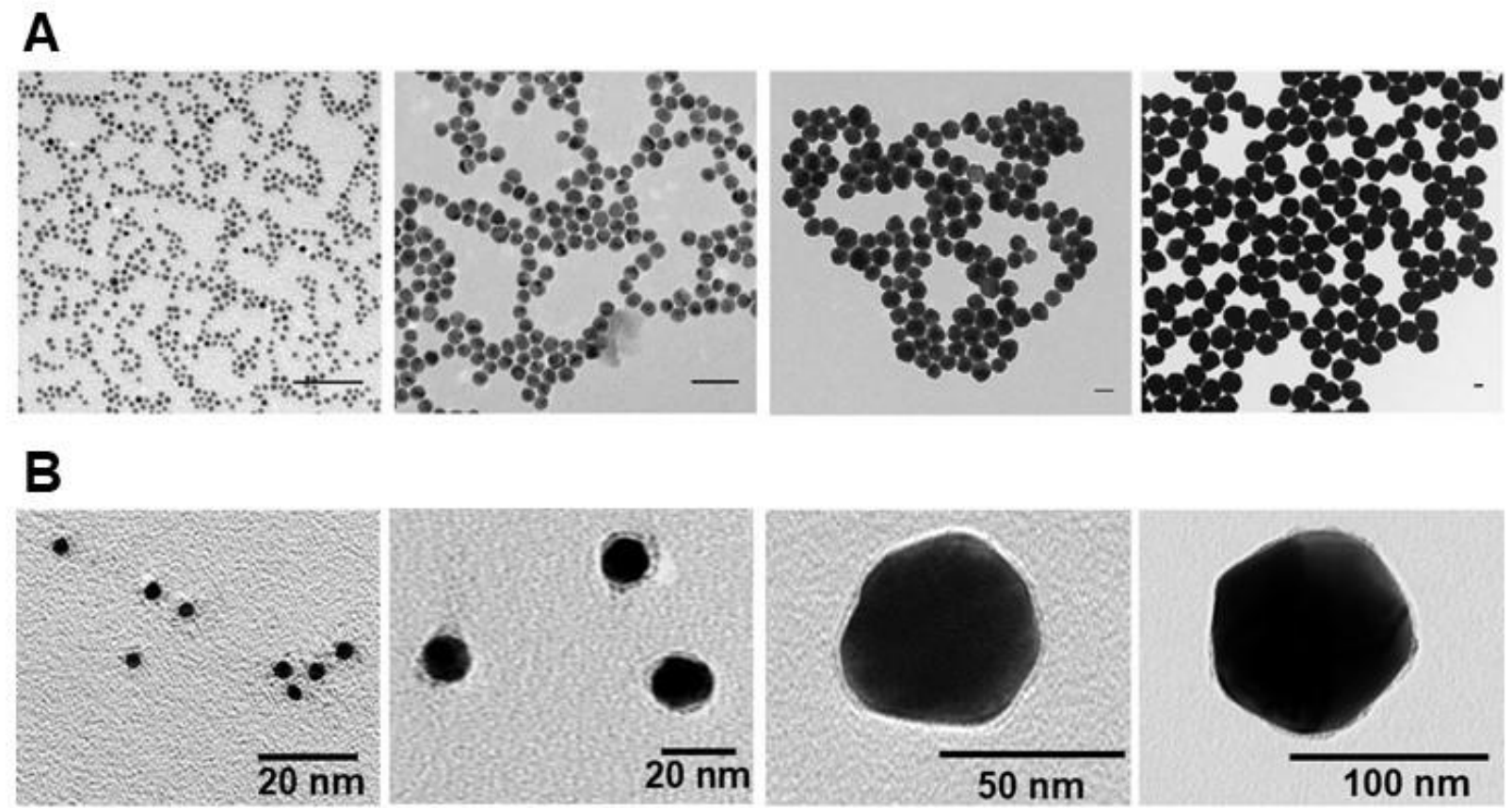

Fig. S1. Nanoparticle vaccine characterization. (A) TEM images of 5, 15, 50, and $100 \mathrm{~nm}$ (left to right) citrate-coated gold nanoparticles (citrate-AuNPs). The scale bars in each figure is $50 \mathrm{~nm}$. (B) TEM images of ovalbumin-coated gold nanoparticles (OVA-AuNPs) with core sizes of 5, 15, 50, and $100 \mathrm{~nm}$ (left to right).

Table. S1. Physicochemical properties of nanoparticle vaccines

\begin{tabular}{|c|c|c|c|c|c|}
\hline \multicolumn{2}{|c|}{ Nanoparticle } & \multicolumn{4}{|c|}{ Physicochemical Properties } \\
\hline Size & $\begin{array}{l}\text { Surface } \\
\text { Ligands }\end{array}$ & $\begin{array}{c}\text { Inorganic } \\
\text { Diameter }(\mathrm{nm})\end{array}$ & $\begin{array}{l}\text { Hydrodynamic } \\
\text { Diameter }(\mathrm{nm})\end{array}$ & $\begin{array}{c}\zeta \text { Potential } \\
(\mathrm{mV})\end{array}$ & $\lambda_{\text {LSPR }}(\mathrm{nm})$ \\
\hline 5 & $\begin{array}{l}\text { Citrate } \\
\text { OVA }\end{array}$ & $4.6 \pm 0.1$ & $\begin{array}{c}8.9 \pm 0.9 \\
18.7 \pm 2.6\end{array}$ & $\begin{array}{c}-9.9 \pm 2.0 \\
-12.6 \pm 0.3\end{array}$ & $\begin{array}{l}515 \\
520\end{array}$ \\
\hline 15 & $\begin{array}{l}\text { Citrate } \\
\text { OVA }\end{array}$ & $15.1 \pm 0.6$ & $\begin{array}{l}21.8 \pm 2.4 \\
82.2 \pm 9.3\end{array}$ & $\begin{array}{c}-8.0 \pm 0.8 \\
-20.4 \pm 0.2\end{array}$ & $\begin{array}{l}521 \\
528\end{array}$ \\
\hline 50 & $\begin{array}{l}\text { Citrate } \\
\text { OVA }\end{array}$ & $48.2 \pm 2.0$ & $\begin{array}{c}60.8 \pm 1.5 \\
125.3 \pm 7.9\end{array}$ & $\begin{array}{l}-22.9 \pm 0.5 \\
-23.0 \pm 0.2\end{array}$ & $\begin{array}{l}531 \\
548\end{array}$ \\
\hline 100 & $\begin{array}{l}\text { Citrate } \\
\text { OVA }\end{array}$ & $112.0 \pm 3.7$ & $\begin{array}{l}112.5 \pm 3.7 \\
167.5 \pm 5.9\end{array}$ & $\begin{array}{l}-25.7 \pm 3.1 \\
-20.2 \pm 0.2 \\
\end{array}$ & $\begin{array}{l}570 \\
585\end{array}$ \\
\hline
\end{tabular}




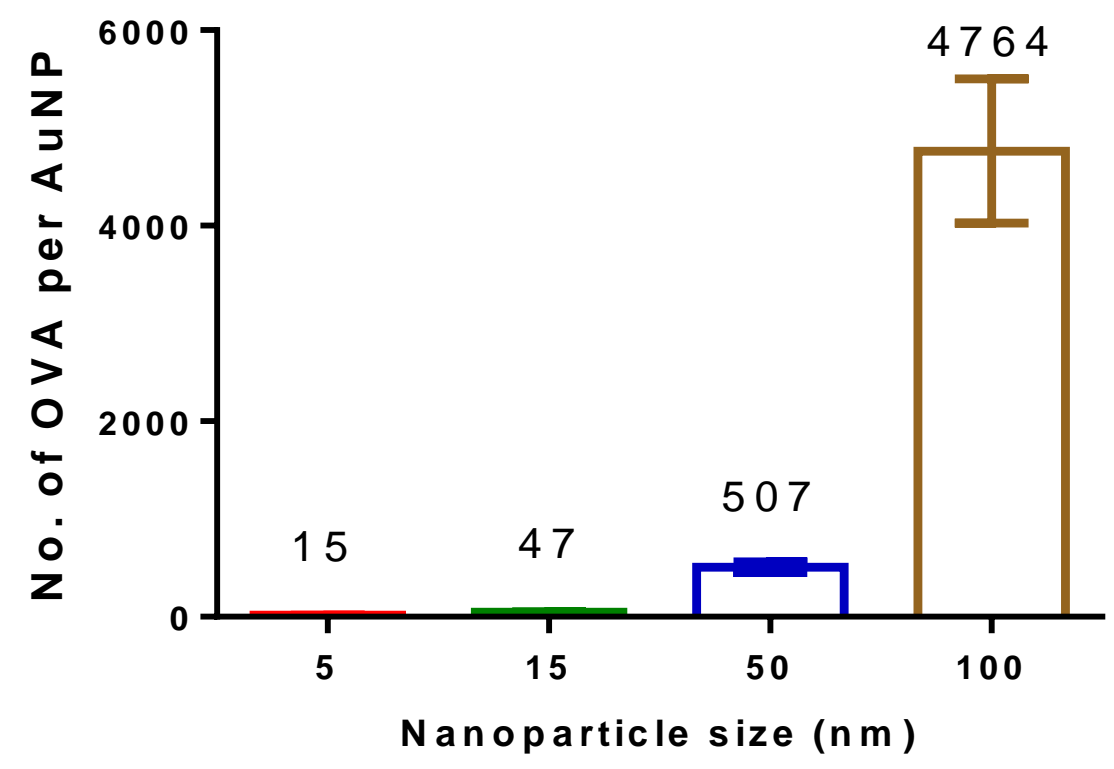

Fig. S2. Quantification of numbers of OVA protein on AuNPs using bicinchoninic acid (BCA) assay. The injection dose is normalized based on the same total amount of OVA antigen (10 $\mu \mathrm{g})$ for each injection. 


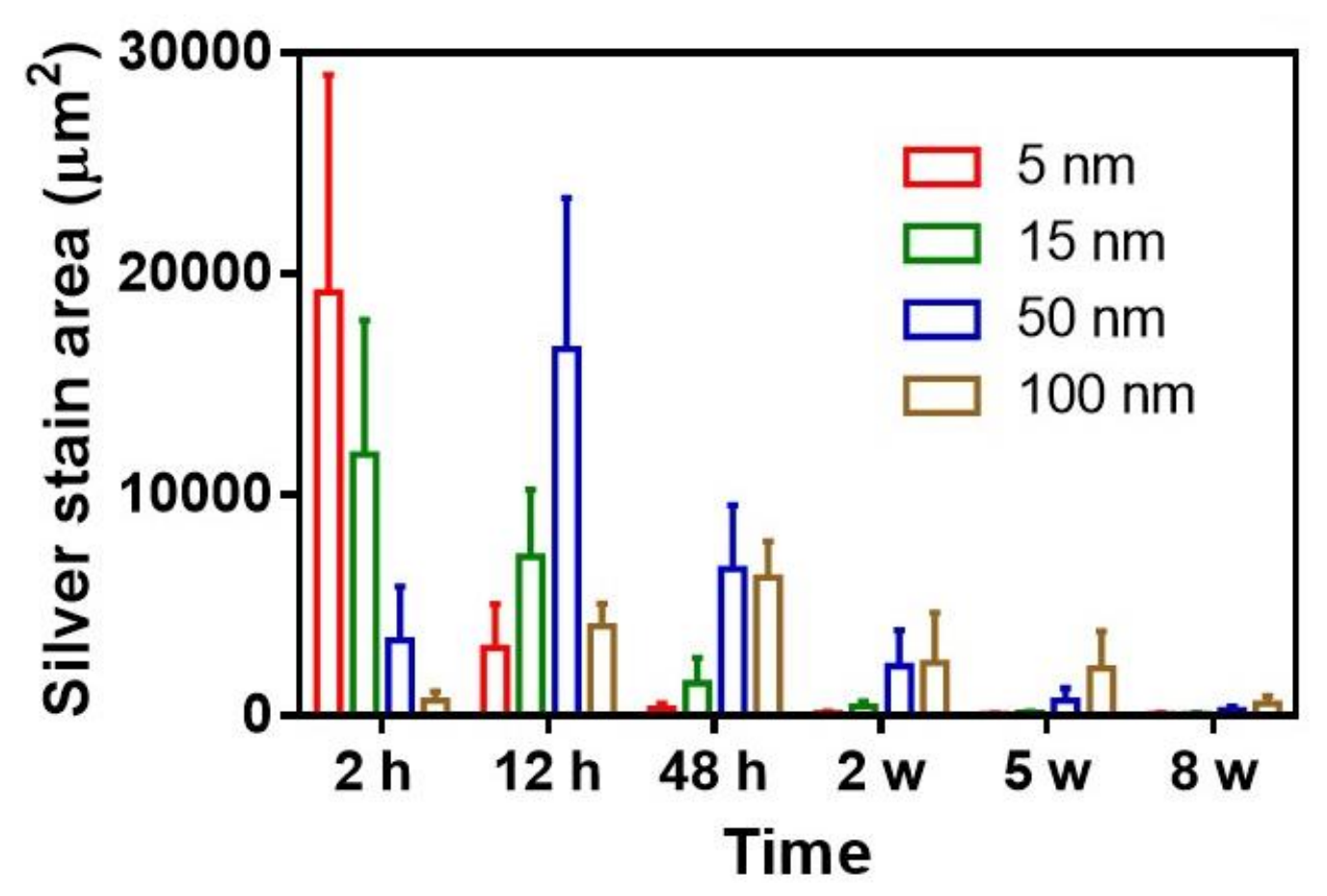

Fig. S3. Quantification of silver stained area in histology images of different sizes of OVAAuNP retention in lymph node follicles over 8 weeks. Histology images of different OVAAuNP vaccine sizes cleared or retained in lymph node follicles after various times (from 2 hours to 8 weeks) post intradermal footpad injection into C57BL/6 mice $(\mathrm{n}=4$ mice/group). Lymph node follicles of sentinel (axillary, brachial and popliteal) lymph nodes were collected. Data collected from 10 lymph node follicles $(n=4)$. The injection dose was normalized based on the same OVA antigen amount $(10 \mu \mathrm{g})$ for each nanoparticle size. 

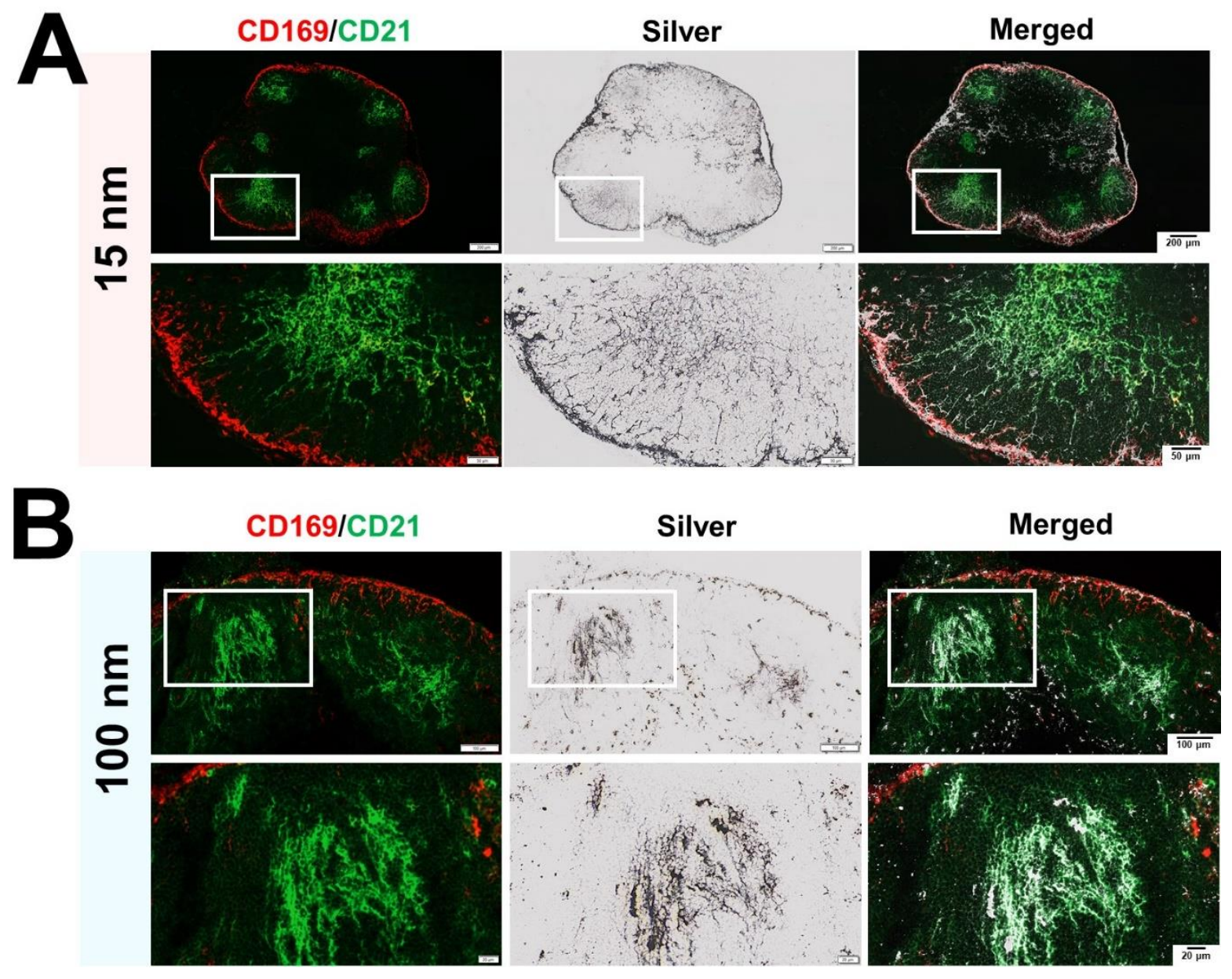

Fig. S4. FDC networks involved in nanoparticle sequestration in lymph node follicles. Histology study of (A) $15 \mathrm{~nm}$ and (B) $100 \mathrm{~nm}$ OVA-AuNP sequestration in lymph node follicles associated with FDC networks at 2 hours and 48 hours post intradermal footpad injection. Gold nanoparticle signals colocalized in the area of FDC networks (CD21 green; CD169 red; Silver black). 
A

\section{FDC networks (CD21)}

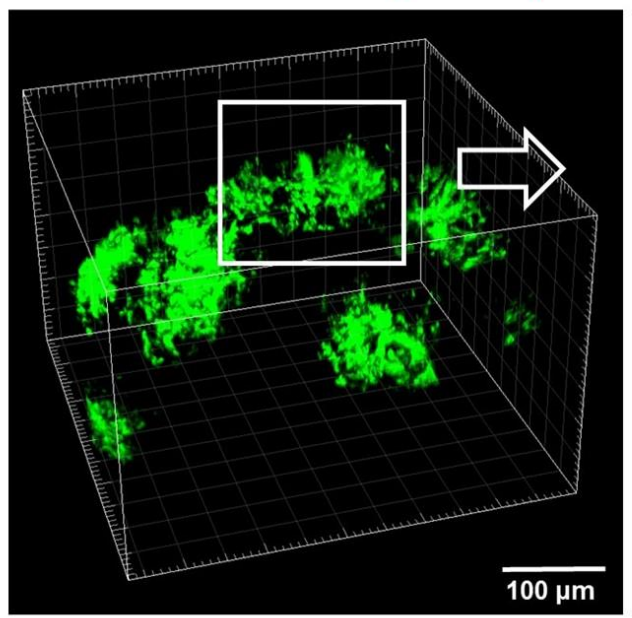

B

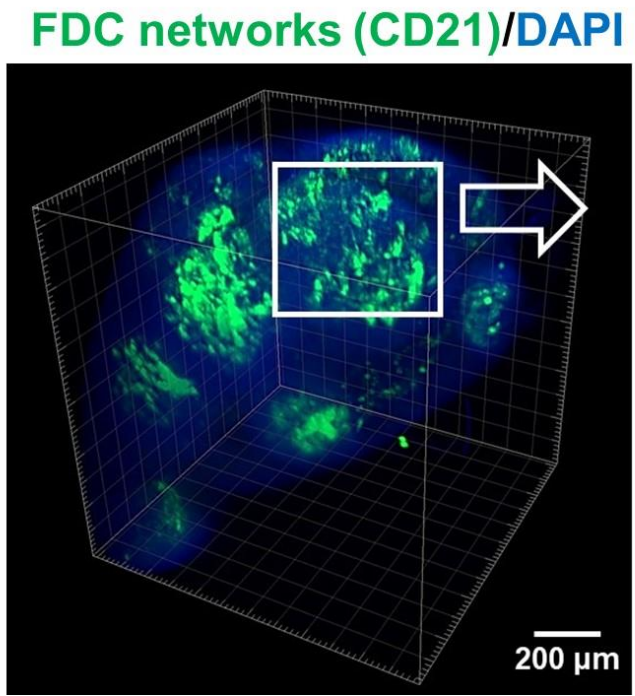

OVA-AuNPs/CD21 OVA-AuNPs/CD21
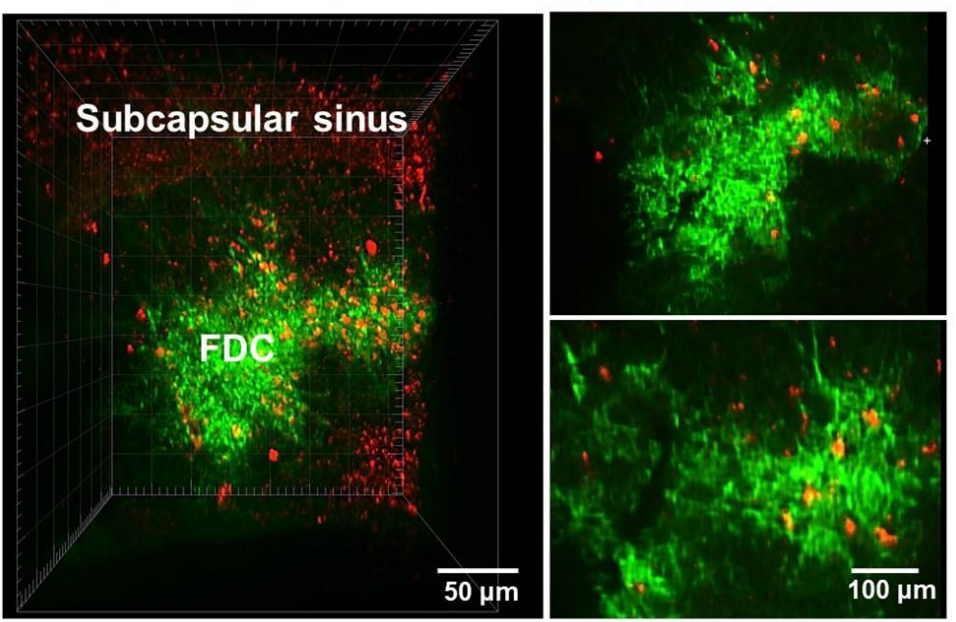
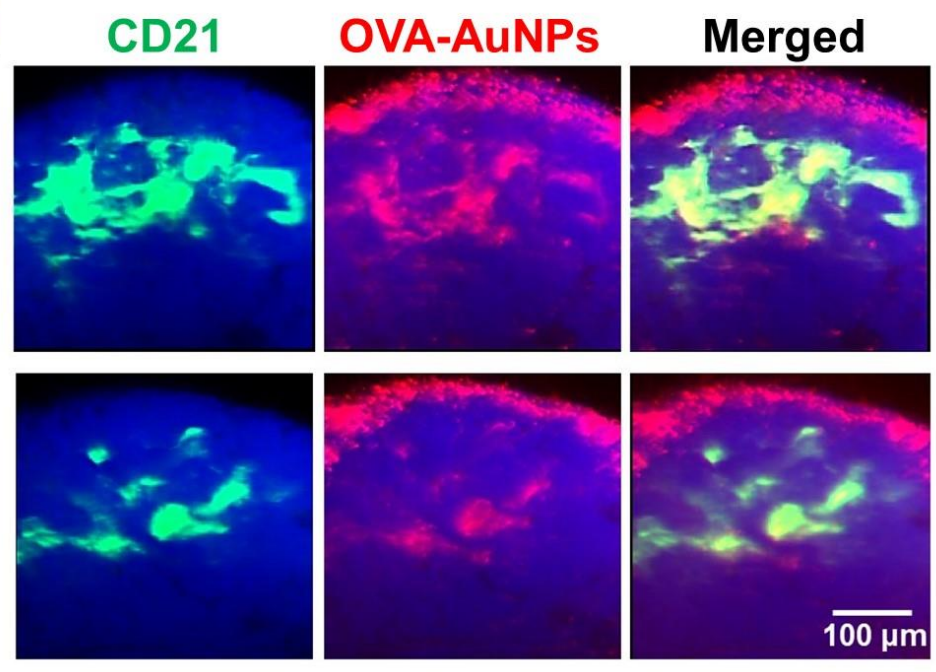

Fig. S5. 3D images of $50 \mathrm{~nm}$ OVA-AuNPs associated with FDC networks in lymph node follicles after CLARITY processing. Sentinel lymph nodes were isolated and cleared after 48 hours post intradermal footpad injection into C57BL/6 mice ( $\mathrm{n}=4$ mice/group). (A) OVA-AuNPs deposited on FDC $\left(\mathrm{CD} 21^{+}\right)$networks. (CD21 green; OVA-AuNP red). (B) Colocalization of OVAAuNPs with FDC networks in lymph node follicles (CD21 green; OVA-AuNP red). 


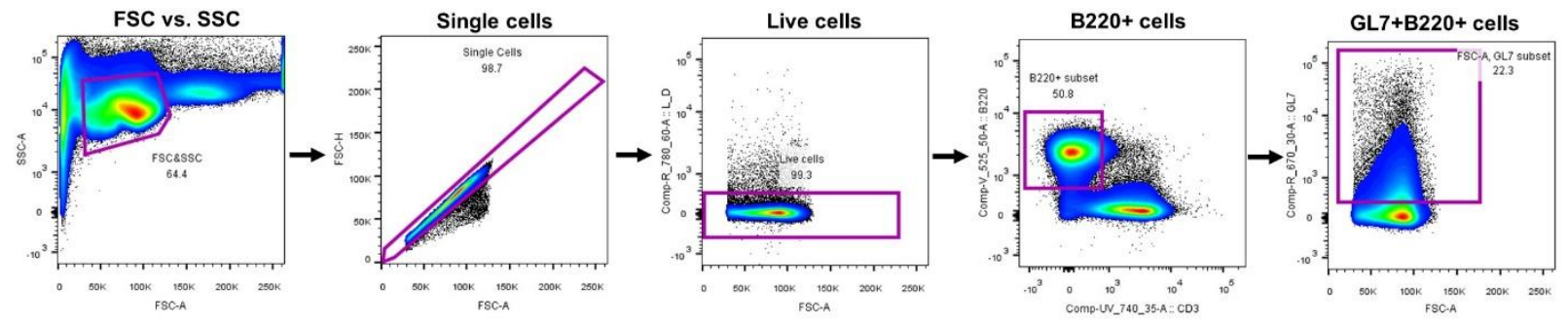

Fig. S6. Gating strategy for analyzing germinal center B cells after 5 weeks of immunization.

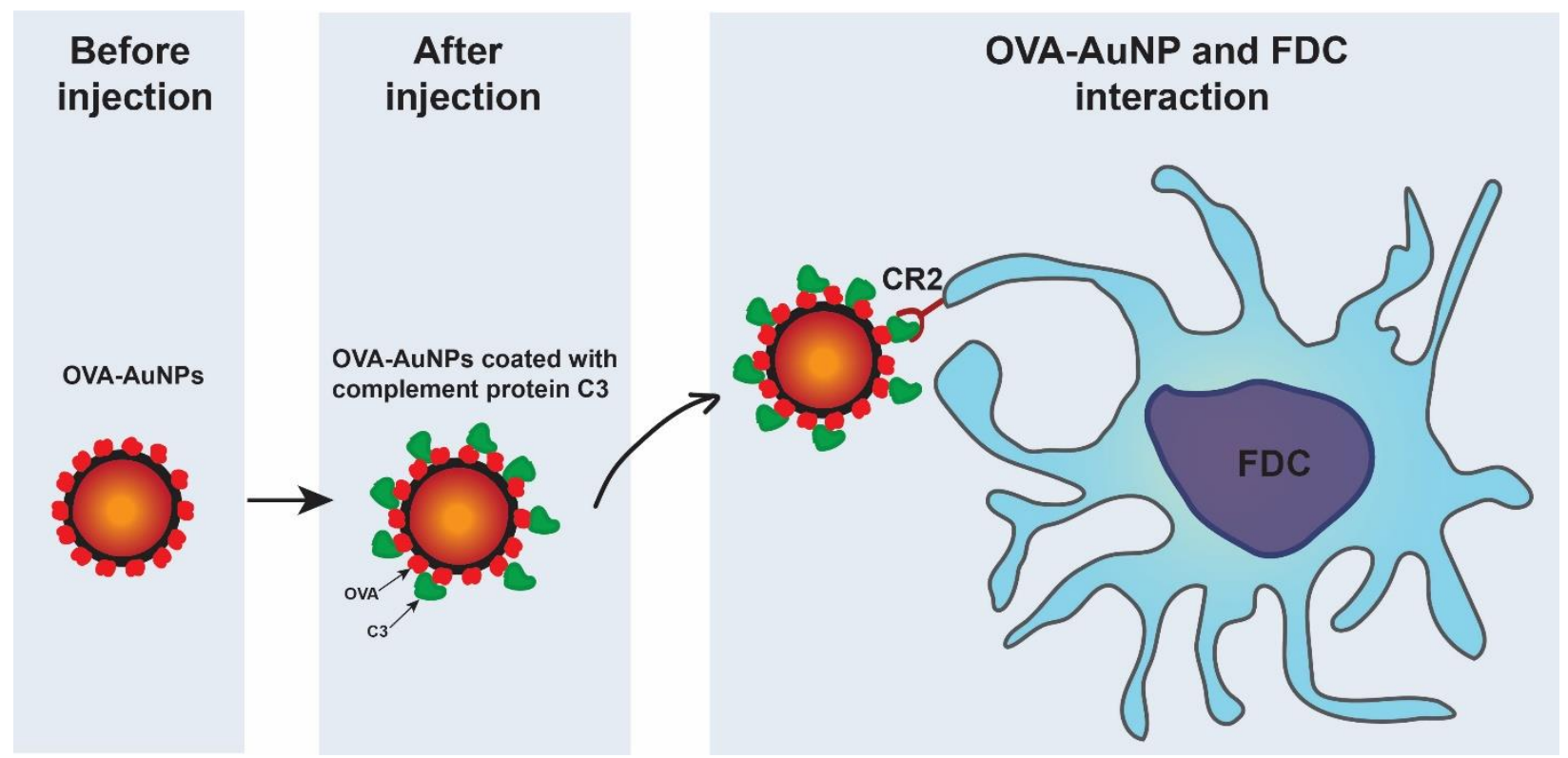

Fig. S7. Complement protein C3 opsonized on the OVA-AuNP surface mediating the interaction with the FDC through complement receptor 2 (CR2). 


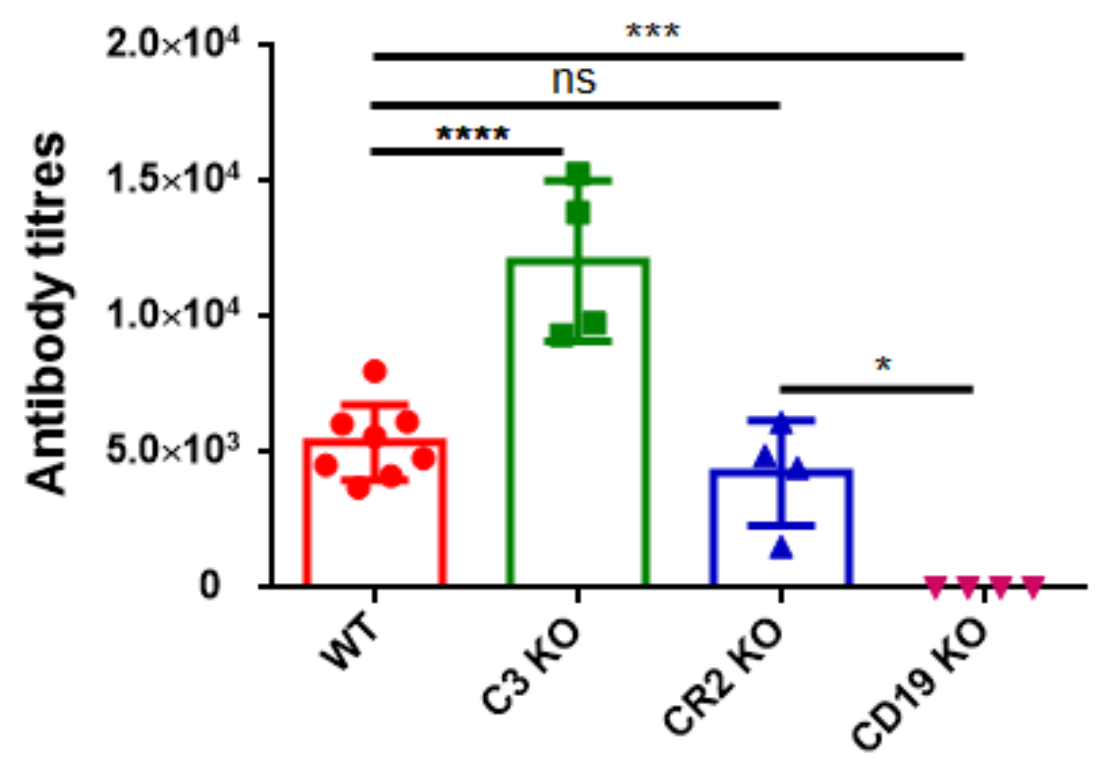

Fig. S8. Antigen-specific antibody production in sera are assessed after injection into wild type or knockout mice at 5 weeks. $50 \mathrm{~nm}$ OVA-AuNPs were injected into wild type, and C3, CR2 and CD19 receptor knockout mice and mice were sacrificed after 5 weeks ( $n=4$-8/group of mice in $\mathrm{C} 57 \mathrm{BL} / 6$ genetic background).

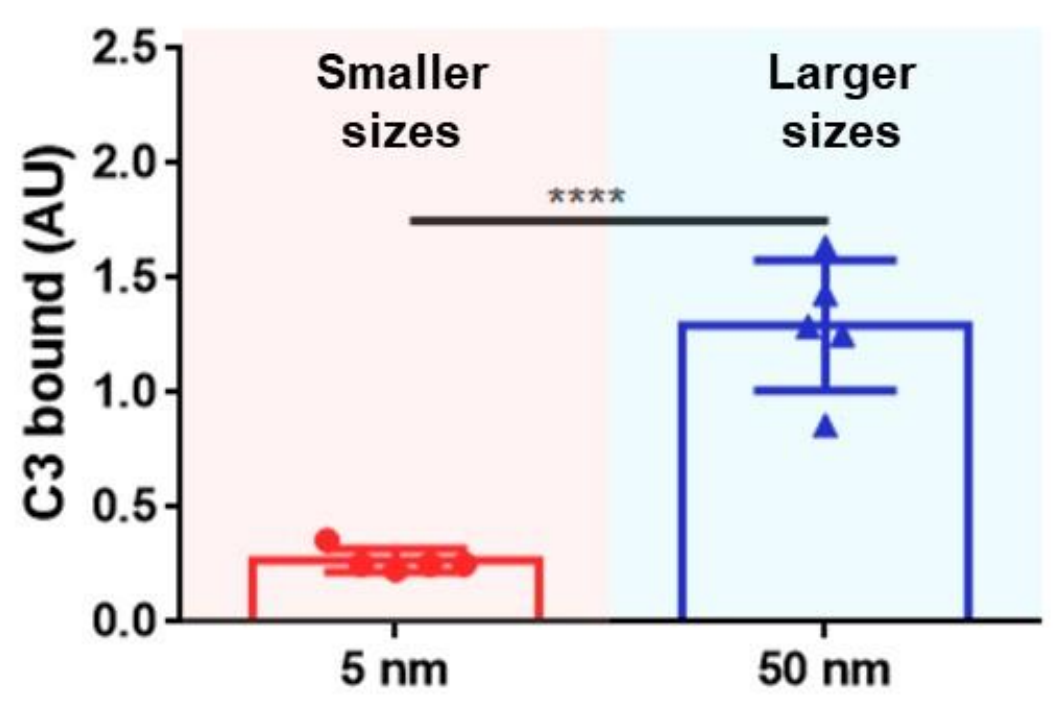

Fig. S9. Larger nanoparticles induce greater complement opsonization than smaller ones. Wild type mice serum was added to OVA-AuNP vaccine pre-coated plate in vitro. C3 deposition was tested using ELISA (AU stands for arbitrary units, $\mathrm{n}=5$ ). Graphs represent mean $\pm \mathrm{SD}$; ****P $<0.0001$. All data was analyzed using an unpaired $t$ test. 
References:

1. Chou, L. Y. T.; Zagorovsky, K.; Chan, W. C. W. Nature nanotechnology 2014, 9 (2), 148155.

2. Frens, G. Nature Physical Science 1972, 241.

3. Perrault, S. D.; Chan, W. C. W. Journal of the American Chemical Society 2009, 131 (47), 17042-17043.

4. Schneider, C. A.; Rasband, W. S.; Eliceiri, K. W. Nat Methods 2012, 9 (7), 671-675.

5. Syed, A. M.; Sindhwani, S.; Wilhelm, S.; Kingston, B. R.; Lee, D. S. W.; Gommerman, J. L.;

Chan, W. C. W. Journal of the American Chemical Society 2017, 139 (29), 9961-9971.

6. Sindhwani, S.; Syed, A. M.; Wilhelm, S.; Glancy, D. R.; Chen, Y. Y.; Dobosz, M.; Chan, W. C. W. ACS nano 2016, 10 (5), 5468-5478.

7. Tokatlian, T.; Read, B. J.; Jones, C. A.; Kulp, D. W.; Menis, S.; Chang, J. Y. H.; Steichen, J. M.; Kumari, S.; Allen, J. D.; Dane, E. L.; Liguori, A.; Sangesland, M.; Lingwood, D.; Crispin, M.; Schief, W. R.; Irvine, D. J. Science 2018, 363 (6427), 649-654.

8. Bachmann, M. F.; Jennings, G. T. Nature reviews. Immunology 2010, 10 (11), 787-796. 